\title{
EFECTO DE LA SUPLEMENTACIÓN DE DOS AGENTES CAPACITANTES EN MEDIO DE FECUNDACION PARA LA PRODUCCIÓN IN VITRO DE EMBRIONES EN ALPACAS (Vicugna pacos)
}

\section{Effect of the supplementation of two capacitive agents in the fertilization medium for the in vitro production of embryos in alpacas (Vicugna pacos)}

\author{
Walter Palomino-Guerrera ${ }^{*}$ (D); Mijaíl Contreras ${ }^{2}$; ; Cesar Olaguivel ${ }^{3}$ (D)
}

'Estación

Experimental

Agraria

Chumbibamba.

Dirección de

Desarrollo

Tecnológico

Agrario. Instituto

Nacional de

Innovación Agraria

(INIA).

Andahuaylas,

Apurímac, Perú

2 Laboratorio de

Biotecnología

Reproductiva.

Estación

Experimental

Agraria Canaán.

Instituto Nacional

de Innovación

Agraria, Ayacucho, Perú

3 Laboratorio de Producción y Salud en Camélidos Sudamericanos, Medicina

Veterinaria,

Universidad

Nacional de San

Cristóbal de

Huamanga,

Ayacucho, Perú.

* Corresponding author:

Walter Palomino

Guerrera

E-mail:

mvpalomino92@gmai I.com

Recibido: 02/07/2020

Aceptado 19/07/2020

Publicado: $21 / 08 / 2020$

\begin{abstract}
The present study aims to evaluate the effect of heparin and PHE (penicillamine, hypotaurine and epinephrine) in the fertilization medium on the in vitro production of embryos in alpacas. The ovaries were transported in $0.9 \%$ physiological saline with gentamicin at $37^{\circ} \mathrm{C}$ for 3 hours. 227 ovaries were used, recovering 1132 oocytes of quality I, II and III; and matured in vitro for $34 \mathrm{~h}$. The mature oocytes were randomly distributed in four culture medium treatments, which were supplemented with $2 \%$ heparin and PHE according to the following distribution: $\mathrm{T} 1=$ Control; $\mathrm{T} 2=$ Heparin; $\mathrm{T} 3=\mathrm{PHE} ;$ $\mathrm{T} 4=\mathrm{PHE}+$ heparin. Then $1 \times 10^{6}$ sperm $/ \mathrm{ml}$ selected by the Percoll gradient method $(45 / 90 \%)$ and incubated for $18 \mathrm{~h}$. Finally, were cultivated in SOF culture medium for 7 day. The cleavage rate at $24 \mathrm{~h}$ in culture were $16.53,19.92,21.42$ and $23.90 \%$ for $\mathrm{T} 1, \mathrm{~T} 2, \mathrm{~T} 3$ and $\mathrm{T} 4$, respectively. The group $T 4$ was difference statistically with groups $T 1, T 2$ and $T 3(P<0.05)$. The morulae rate at day 7 were $24.23,29.49,35.00$ and $35.30 \%$ for $\mathrm{T} 1, \mathrm{~T} 2, \mathrm{~T} 3$ and $\mathrm{T} 4$, respectively, with statistical difference between $\mathrm{T} 1$ and $\mathrm{T} 2$ with respect to $\mathrm{T} 3$ and $\mathrm{T} 4$. The blastocysts rate at day 7 were $3.60,3.25,4.52$ and $6.34 \%$ for $\mathrm{T} 1, \mathrm{~T} 2, \mathrm{~T} 3$ and $\mathrm{T} 4$, respectively, with no statistical difference between treatments. Regarding quality, the embryos (morulae and blastocysts) produced in vitro from the treatments with the use of PHE + heparin and PHE capacitors stood out $(p \leq 0.05)$ with excellent quality embryos In conclusion, the use of heparin and PHE in fertilization medium increases the in vitro production of excellent quality embryos.
\end{abstract}

Keywords: Fertilization, heparin, IVF, alpaca.

\section{RESUMEN}

El presente estudio tuvo como objetivo evaluar el efecto de la heparina y PHE (penicilamina, hipotaurina y epinefrina) en el medio de fecundación en la producción in vitro de embriones en alpacas. Los ovarios fueron transportados en solución salina fisiológica al $0.9 \%$ con gentamicina a $37^{\circ} \mathrm{C}$ durante 3 horas. Se utilizaron 227 ovarios, recuperándose 1132 ovocitos de calidad I, II y III; y madurados in vitro por $34 \mathrm{~h}$. Los ovocitos maduros se distribuyeron de forma aleatoria en cuatro tratamientos de medio de fecundación, las cuáles fueron suplementados con heparina al $2 \%$ y PHE según la siguiente distribución: $\mathrm{T} 1=$ Control; $\mathrm{T} 2=$ Heparina; $\mathrm{T} 3=\mathrm{PHE}$; T4=PHE + heparina. Luego se añadió $1 \times 10^{6}$ espermatozoides/ml seleccionados por el método gradiente de Percoll $(45 / 90 \%)$ e incubados por $18 \mathrm{~h}$. Finalmente se cultivaron en medio de cultivo SOF durante 7 días. Los porcentajes de clivaje a las $24 \mathrm{~h}$ en cultivo fueron de $16.53,19.92,21.42$ y $23.90 \%$ para los T1, T2, T3 y T4, respectivamente, habiendo diferencia estadística significativa del T1, T2 y T3 con respecto al T4 $(\mathrm{P}<0.05)$. Los porcentajes de mórulas al día 7 de cultivo fueron $24.23,29.49,35.00$ y $35.30 \%$ para los T1, T2, T3 y T4, respectivamente, habiendo diferencia estadística del T1 y T2 con respecto al T3 y T4. Los porcentajes de blastocistos al día 7 de cultivo fueron $3.60,3.25,4.52$ y $6.34 \%$ para los T1, $\mathrm{T} 2$, T3 y T4, respectivamente, sin diferencia estadística entre tratamientos. En cuanto a calidad, los embriones (mórulas y blastocistos) producidos in vitro de los tratamientos con uso de agentes capacitantes PHE+ heparina y PHE destacaron $(p \leq 0.05)$ con embriones de excelente calidad. En conclusión, el uso de la heparina y PHE + Heparina en medio de fecundación incrementa la producción in vitro de embriones de excelente calidad.

Palabras clave: Fecundación, heparina, FIV, alpaca. 


\section{INTRODUCCION}

Las deficiencias en los esquemas de manejo reproductivo han contribuido a la desmejora en la calidad genética en alpacas y con una consiguiente disminución de los ingresos de la población altoandina (Huanca, 2015). Las biotecnologías reproductivas son herramientas de mucho beneficio para los productores pecuarios, siendo desarrolladas con la finalidad de aumentar el progreso genético del animal (Cabrera et al., 2009) hasta llegar a un nivel, en el cual es posible la manipulación dirigida del genoma o determinados genes con mayor rapidez (Clement-Sengewald et al., 1993).

La limitada información existente sobre el desarrollo de protocolos de fecundación in vitro (FIV) en camélidos domésticos sugiere estudiar y evaluar los factores que contribuyan a obtener resultados similares a los observados en otras especies de interés económico (Huanca et al., 2014). Son muchos los factores que aún faltan dilucidar para estandarizar la fecundación in vitro en los camélidos (Trasorras y Miragaya, 2016). A pesar de que los embriones producidos in vitro son de menor calidad que los obtenidos in vivo (Herradón et al., 2007), con los pocos trabajos realizados hasta el momento, se ha alcanzado resultados alentadores (Trasorras y Miragaya, 2016). Son estas las razones por la cual se necesita priorizar investigaciones que permitan contribuir a diseñar alternativas biotecnológicas para los programas de mejoramiento genético en los camélidos domésticos (Huanca et al., 2007). En alpacas se han reportado ovocitos morfológicamente normales y fisiológicamente viables posterior a la vitrificación y descongelación (Ruiz et al., 2011).

La producción in vitro de embriones consta de un procedimiento en laboratorio, donde los ovocitos recuperados son sometidos a procesos de maduración in vitro (MIV) utilizando diversos medios con la adición de gonadotropinas y factores de crecimiento (Gonella et al., 2013), insumos que son indispensables para la maduración. En la etapa de fecundación in vitro (FIV) los ovocitos madurados son incubados con los espermatozoides, para ello los espermatozoides son sometidos a tratamientos de capacitación espermática in vitro, donde adquieren capacidad fecundante y se separan los espermatozoides vivos de los componentes seminales y crioprotectores (Gomez et al., 2013) para iniciar su capacitación y desencadenar la reacción acrosómica (Palma 2001 citado en Ruiz, 2018). Por lo tanto, el medio de fecundación debe favorecer la actividad espermática y penetración de la zona pelúcida (Gonella et al., 2013). Trabajos realizados por Rodriguez, (2012) indican la utilización de inhibidores sintéticos de proteasas específicos para tratar los espermatozoides y conservar el acrosoma intacto hasta el momento de la fecundación.

El uso de agentes capacitantes en medio cultivo es una práctica habitual en muchos laboratorios y estudios realizados en alpacas no son abundantes. El efecto in vitro de la heparina, un glicosaminoglicano sulfatado, que están presente en el tracto reproductivo de la hembra, podría desempeñar un papel importante en el proceso de fecundación in vitro (Dapino et al., 2006), así también, las catecolaminas y los aminoácidos, como la penicilamina, hipotaurina y epinefrina (PHE) tiene efectos benéficos sobre los resultados obtenidos, ya que actúa como antioxidante sobre el medio, estimulante de la capacitación espermática, aumenta la motilidad, penetración de ovocitos y reacción acrosómica (Andrews y Bavister, 1989).
Posteriormente, los ovocitos incubados con espermatozoides (presuntos cigotos) son sometidos a cultivo in vitro (CIV) en medios que contengan fuentes de energía, aminoácidos y factores de crecimiento con el fin de mantener su sobrevivencia y desarrollo (Gonella et al., 2013). Protocolos con la adición de cisteamina al medio de cultivo, mejora la tasa de desarrollo embrionario in vitro hasta el estadio de blastocisto (Quintanilla et al., 2015). A pesar de ello, los medios de cultivo todavía necesitan ser mejorados sensiblemente, puesto que el cultivo de los embriones en condiciones in vivo incrementa notablemente la calidad de estos (Herradón et al., 2007).

Según Ratto et al. (2015) el impedimento más complejo para lograr un avance significativo del método de FIV es la información científica sobre la fecundación in vitro en camélidos. Asimismo, no hay reportes sobre el efecto de agentes capacitantes sobre la producción in vitro de embriones. El objetivo del presente estudio fue evaluar el efecto de la heparina y el PHE en el medio de fecundación (TALP-FIV) en la producción in vitro de embriones de alpaca.

\section{MATERIALES Y MÉTODOS}

\section{Lugar de estudio}

La investigación se realizó en el Laboratorio de Biotecnología Reproductivas de la Estación Experimental Agraria Canaán, del Instituto Nacional de Investigación Agraria (INIA).

\section{Producción in vitro de embriones}

Los ovarios y testículos de alpacas fueron colectadas de animales mayores a 2 años beneficiados en el Camal Municipal de Pilpichaca-Huancavelica, ubicada en las coordenadas: Latitud: 13.3303 , Longitud: $74.9769,13^{\circ} 19^{\prime} 49^{\prime \prime}$ Sur, $74^{\circ} 58^{\prime}$ 37" Oestea, a $4.092 \mathrm{msnm}$. Los ovarios fueron depositados en un termo que contiene solución salina fisiológica al $0.9 \%$ más gentamicina con concentración de $80 \mathrm{mg} / \mathrm{ml}$ a $37^{\circ} \mathrm{C}$ de temperatura; y trasportados por 2 a 3 horas. Una vez en el laboratorio, se lavaron tres veces con solución salina al $0.9 \%$ más antibiótico a $37^{\circ} \mathrm{C}$ para eliminar los restos de sangre e impurezas.

\section{Maduración de ovocitos}

La recuperación de complejo ovocitos-cúmulos (COCs) se realizó de folículos que tenían 3 a $7 \mathrm{~mm}$ de diámetro mediante la técnica Slicing (corte) en placas petri que contenían medio de manipulación. Los COCs fueron clasificados en 4 grados en base a los criterios del Laboratorio de Biotecnología Reproductiva de la EEA-Canaán:

- Grado I: COCs con 5 capas o más de células de cúmulos compactas, con citoplasma homogéneo,

- Grado II: COCs con 3 a 4 capas de células de cúmulos compactas, con citoplasma homogénea,

- Grado III. COCs con 1 a 2 capas de células de cúmulos compactas, citoplasma con presencia ligeramente granular

- Gardo IV: COCs totalmente desnudo o parcialmente, con citoplasma granular.

Los ovocitos seleccionados fueron cultivados en medio de MIV, constituida por (TCM-199), piruvato de sodio $(0.011 \mathrm{~g} / \mathrm{mL}$ ), 17.6 estradiol $(22.2 \mathrm{mg} / \mathrm{mL})$, L-glutamina $(0.015 \mathrm{~g} / \mathrm{mL}), \mathrm{FSH}$ 
$(0.5 \mathrm{mg} / \mathrm{mL})$, SFB $(5 \%)$, gentamicina $(80 \mathrm{mg} / \mathrm{mL})$. Los ovocitos fueron puestos a madurar por 36 horas en una incubadora (BIONEX modelo VS-9160GC) en condiciones de $38.5^{\circ} \mathrm{C}$ de temperatura, $5 \%$ de $\mathrm{CO}_{2}, 5 \%$ de $\mathrm{O}_{2}$ y $90 \%$ de humedad relativa, colocados en placas de 4 pocillos que contenían 500uL de medio MIV. Cabe señalar que en ninguna de las fases de FIV se utilizaron con aceite mineral para cubrir los medios.

\section{Recuperación y selección de espermatozoides}

Los espermatozoides se recuperaron de la cola del epidídimo, de testículos que fueron extraídos de animales mayores de 3 años beneficiados en el Camal Municipal de PilpichacaHuancavelica. A la cola del epidídimo se realizaron cortes trasversales y longitudinales, de donde se recuperaron los espermatozoides en el dilutor comercial (Andromed) preparado con agua bidestilada en relación de 1:4, la cual estaba depositado en una placa petri.

Los espermatozoides recuperados de la cola de epidídimo se depositaron en vial de $1 \mathrm{~mL}$ contenidos de gradiente de densidad Percoll (45/90\%), la cual fue centrifugado a 2000 RPM por 20 minutos, se retiró el sobrenadante y luego se reconstituyó con 100 $\mu$ l de TALP-SPER, después se centrifugó a 1000 RPM por 10 minutos y una vez eliminado el sobrenadante el pellet fue reconstituido con medio TALP-FIV.

\section{Fecundación in vitro}

Finalizado el tiempo de maduración, los ovocitos supuestamente maduros se lavaron y se distribuyeron en forma aleatoria en cuatro tratamientos de medios de fecundación, que estuvo compuesta por medio TALP-FIV, base suplementado con piruvato de sodio, gentamicina y los agentes capacitantes heparina y $\mathrm{PHE}$, como sigue:

Tratamiento 1 = Control

Tratamiento 2 = Heparina $2 \%(40 \mu \mathrm{L} / \mathrm{mL})$

Tratamiento $3=$ PHE $(2 \mathrm{mM}$ de Penicilamina, $1 \mathrm{mM}$ de Hipotaurina y $250 \mathrm{mM}$ de epinefrina) $(86 \mu \mathrm{L} / \mathrm{mL})$

Tratamiento $4=$ PHE $(2 \mathrm{mM}$ de Penicilamina, $1 \mathrm{mM}$ de Hipotaurina y $250 \mathrm{mM}$ de epinefrina) $(86 \mu \mathrm{L} / \mathrm{mL})+$ Heparina $2 \%(40 \mu \mathrm{L} / \mathrm{mL})$

Los medios de fecundación de los 4 tratamientos fueron a incubados por un tiempo de 30 minutos antes de colocar los ovocitos. Posteriormente, los ovocitos madurados fueron lavados en FIV y se les añadió una suspensión de $10 \mu \mathrm{L}\left(1 \times 10^{6}\right.$ espermatozoide/ml) de espermatozoides seleccionados por gradiente de densidad $\mathrm{e}$ incubados por 18 horas en condiciones de $38.5^{\circ} \mathrm{C}, 5 \%$ de $\mathrm{CO}_{2}, 5 \% \mathrm{O}_{2}$ y una humedad de $90 \%$.

\section{Cultivo de embriones}

18 horas post FIV, los presuntos cigotos se pipetearon en los mismos pocillos para denudar el exceso de las células del cúmulus, posteriormente fueron transferidos a medio de cultivo SOF (fluido oviductal sintético) y puestos en bolsas de polietileno con mezcla de gases $\left(5 \%\right.$ de $\mathrm{O}_{2}, 5 \%$ de $\mathrm{CO} 2$ y $90 \%$ de $\mathrm{N}_{2}$ ) en incubadora a $38.5^{\circ} \mathrm{C}$ durante 7 días hasta la evaluación de los embriones (mórulas, blastocistos) según tratamiento. A 72 horas cultivo se realizó el cambio de medio SOF.

\section{Clasificación de embriones}

Pasado los 7 días de cultivo, se procedió a evaluar el desarrollo embrionario y su calidad. Embriones en desarrollo (mórulas y blastocistos) se clasificaron de excelente (I) a malo (IV), según la Sociedad Internacional de Transferencia Embrionaria IETS.

\section{Análisis estadístico}

Los datos de división y desarrollo embrionario obtenidos de los cuatro tratamientos (agentes capacitantes) fueron analizados mediante análisis de varianza (ANOVA) y para el análisis de medias se utilizaron la prueba de comparación de Duncan. Los datos se procesaron con el programa estadístico SAS versión 9.2.

\section{RESULTADOS}

Para producir embriones in vitro se requiere ovocitos de alta capacidad fecundante. Mediante la técnica de Slicing (corte) se recuperaron un total de 1397 ovocitos entre aptos y no aptos, de los cuales el $81.03 \%$ fueron ovocitos de calidades I, II y III, que se consideraron aptos para la puesta en maduración in vitro. El numero promedio de ovocitos aptos/ovario de alpacas fue de $5.00 \pm 0.42$.

El porcentaje de clivaje (división celular) pasado las 24 horas de cultivo en medio SOF se muestran en Tabla 1, donde se puede evidenciar que el tratamiento con PHE + Heparina y PHE (T4) fueron superiores a los tratamientos Control (T1) y Heparina (T2). La tasa de mórulas (Tabla 1) al día 7 de cultivo en medio SOF fue $24.73 \pm 1.71 \%, 29.41 \pm 1.69 \%$, $35.00+2.96 \%$ y $35.30 \pm 2.64 \%$ para los tratamientos Control, heparina, PHE y PHE + heparina, respectivamente, existiendo diferencia estadística significativa entre tratamientos ( $p \leq 0.05)$, obteniendo mayor porcentaje de mórulas con el tratamiento PHE+ heparina seguido por el PHE.

Tabla 1. Efecto de los agentes capacitantes sobre el porcentaje de clivaje a las 24 horas de cultivo y mórulas y blastocistos al día 7 de cultivo en alpacas.

\begin{tabular}{lcccc}
\hline \multicolumn{1}{c}{ Trat. } & $\begin{array}{c}\text { Ovocitos } \\
\text { fecund. }\end{array}$ & $\begin{array}{c}\text { Clivaje } \\
\mathrm{n}(\%)\end{array}$ & $\begin{array}{c}\text { Mórulas } \\
\mathrm{n}(\%)\end{array}$ & $\begin{array}{c}\text { Blastocistos } \\
\mathrm{n}(\%)\end{array}$ \\
\hline Control & 184 & $30(16.53)^{\mathrm{a}}$ & $43(24.73)^{\mathrm{a}}$ & $7(3.60)^{\mathrm{a}}$ \\
\hline Heparina & 202 & $40(19.92)^{\mathrm{a}}$ & $58(29.49)^{\mathrm{ab}}$ & $7(3.25)^{\mathrm{a}}$ \\
\hline PHE & 207 & $43(21.42)^{\mathrm{ab}}$ & $71(35.00)^{\mathrm{cb}}$ & $9(4.52)^{\mathrm{a}}$ \\
\hline $\begin{array}{l}\text { PHE + } \\
\text { Heparina }\end{array}$ & 243 & $57(23.90)^{\mathrm{b}}$ & $84(35.30)^{\mathrm{c}}$ & $15(6.34)^{\mathrm{a}}$ \\
\hline
\end{tabular}

$a, b, c$ letras diferentes en la misma columna indica que hay diferencia estadística significativa $(p \leq 0.05)$.

Durante la evaluación al día 7 de cultivo se observaron blastocistos temprano (BT), blastocisto (B), blastocisto expandido (BE) y blastocisto eclosionado (BE). Se puede apreciar que hay en menor porcentaje de blastocistos en 
comparación con las mórulas (Tabla 1) y no había diferencia estadística entre los tratamientos ( $p \geq 0.05)$.

En cuanto a calidad de los embriones (mórulas y blastocistos) producidos in vitro, los tratamientos con agentes capacitantes de PHE+ heparina y PHE destacaron $(p \leq 0.05)$ con embriones de excelente calidad (Tabla 2).

Tabla 2. Efecto de los agentes capacitantes sobre la calidad de embriones (mórulas y blastocistos) producidos in vitro en alpacas.

\begin{tabular}{lcccc}
\hline \multicolumn{1}{c}{ Trat. } & $\begin{array}{c}\text { Excelente } \\
\mathrm{n}(\%)\end{array}$ & $\begin{array}{c}\text { Buena } \\
\mathrm{n}(\%)\end{array}$ & $\begin{array}{c}\text { Regular } \\
\mathrm{n}(\%)\end{array}$ & $\begin{array}{c}\text { Malo } \\
\mathrm{n}(\%)\end{array}$ \\
\hline Control & $29(56.9)^{\mathrm{a}}$ & $16(31.4)$ & $5(9.8)$ & $1(2.0)$ \\
Heparina & $37(56.9)^{\mathrm{ab}}$ & $25(38.5)$ & $2(3.1)$ & $1(1.5)$ \\
PHE & $58(72.5)^{\mathrm{cb}}$ & $18(22.5)$ & $1(1.3)$ & $3(3.8)$ \\
PHE + & & & & \\
heparina & $68(71.6)^{\mathrm{c}}$ & $19(20.0)$ & $4(4.2)$ & $4(4.2)$
\end{tabular}

$\overline{a, b, c}$ letras diferentes en la misma columna significa que hay diferencia estadística ( $\mathrm{p} \leq 0.05)$.

\section{DISCUSIÓN}

Las técnicas de recuperación de ovocitos en alpacas ya no es factor limitante para poder establecer protocolos de fecundación in vitro. La técnica de recuperación es clave para obtener de ovocitos de buena calidad y mejor capacidad fecundante. En este estudio la recuperación se realizó empleando el método de Slicing, obteniendo $81.03 \%$ de ovocitos aptos con $5.00 \pm 0.42$ ovocitos/ovario. Similar a los reportados por Vasquez et al., (2015) en alpacas $(61.00 \%$ de ovocitos viables con $10.00 \pm 7.01$ ovocitos/ovario).

Uno de los factores que afecta la calidad de los ovocitos es el tiempo de transporte del ovario, tal como lo reportaron Holt y Pickard, (1999) con largos periodos de transporte a $35-38^{\circ} \mathrm{C}$ ocurre la autolisis celular en los ovarios o cuando se transporta a bajas temperaturas (refrigeración) (Arriaga et al., 2014) afectando la calidad de ovocitos.

La tasa de clivaje es el primer indicador de la producción de embriones in vitro, que expresa el éxito de la fecundación de los ovocitos. Sin embargo, en camélidos existen un bajo número de publicaciones con el uso de agentes capacitantes, determinando tasa de clivaje. Algunos trabajos, Huanca et al., (2014) reportaron utilizando $15.6 \%$ de división a 72 horas para ovocitos madurados por 36 horas y fecundados con adición de PHE + Heparina como agente capacitante. Así mismo, Quispe et al., (2019) reportaron tasas de clivaje de $22.4 \%$. Aunque, Terreros et al., (2015) reportaron tasas de clivaje de fecundación $47 \%$ y $27 \%$ evaluados a las 72 horas post fecundación con espermatozoides congelados en dimetilsulfoxido (DMSO) y Glicerol, respectivamente. La similitud o diferencia de tasa de clivaje a nuestro trabajo posiblemente puede deberse a varios factores protocolo $y$ medios MIV y FIV, método de selección espermática, etc.

En bovinos y ovinos, la técnica de FIV está más estandarizada, por ello que varias publicaciones reportan tasas de clivaje de $82.3 \%$ (Ahuja et al., 2009) y 50.0\% (El-Shahat et al., 2017)
Los embriones de alpacas en distintas etapas de desarrollo se pueden visualizar en figura 1. La tasa de producción in vitro de mórulas en el presente estudio se alcanzó hasta $35.30 \pm 2.64 \%$ con el tratamiento PHE+Heparina. Respecto al porcentaje de mórulas con $\mathrm{PHE}(35 \%)$ no se encontraron reportes ni publicaciones en alpacas. Sin embargo, Contreras et al., (2014) en alpacas, con el uso de Heparina reportaron $15.80 \%$ de mórulas con espermatozoides seleccionado por Percoll y Pérez et al., (2017) reprtaron $16.5 \%$ de mórulas utilizando el método Swim-up, estos resultados son inferiores a los encontrados en el presente estudio, esto posiblemente se deba a la técnica de selección espermática y el método de aspiración folicular en la recuperación de ovocitos. Brogliatti et al. 2000 citado en Gomez, et al., (2013) sugieren que los ovocitos de alpacas serían más sensibles a la aspiración folicular, ya que este método provocaría daños a nivel de los cúmulos del COC's, de esta manera afectan la calidad de los ovocitos.

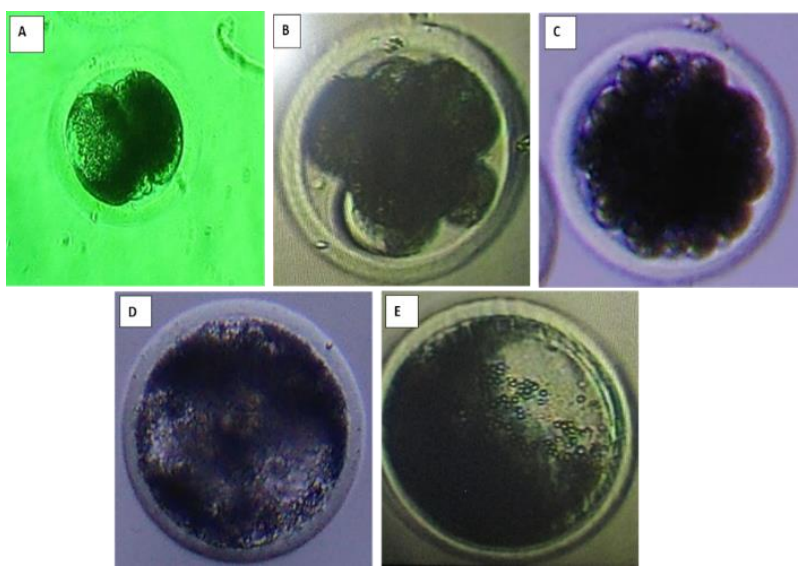

Figura 1. Embriones de alpaca producidos in vitro (200X). A) Clivaje, B) Mórula temprana, C) Mórula compacta D) Blastocisto temprano, E) Blastocisto.

La tasa de blastocistos en nuestro estudio tuvo como valor máximo $6.34 \%$, esto podría haber sido afectado por factores: Composición de medios de cultivo, manejo de los embriones y protocolo aplicado. Utilizando Heparina, Contreras et al. (2014) reportaron $8.4 \%$ de blastocistos, Asimismo, utilizando $\mathrm{PHE}+$ Heparina, Pérez et al. (2017) reportaron $6.4 \%$ de blastocistos, los dos son similares a los reportes de este estudio.

En bovinos, la tasa de blastocisto reportada es bastante superior 19,3\% (Pahuara y Naveros, 2014) y 18.8\% (Urrego et al., 2008) con el uso de heparina y PHE + Heparina, respectivamente en medio FIV. Siendo otra diferencia el uso de medio de cultivo CR I aa.

Obtener embriones de excelente calidad en alpacas es un reto de los laboratorios de FIV, puesto que es un factor primordial para tener la capacidad de implantación de los embriones transferidos. Tener en cuenta que los embriones producidos in vitro son más sensibles que los producidos en vivo. Para maximizar la tasa de preñez es muy importante transferir embriones de excelente y buena calidad, esto quiere decir, que un embrión debería tener la integridad de la membrana, masa embrionaria esférica y simétrica, con blastómeros uniformes en cuanto a tamaño, color y densidad. En camélidos, 
hay pocas publicaciones donde clasifican la calidad morfológica de los embriones. Cardenas et al. (2015) en vicuñas recuperaron in vivo embriones con $55.56 \%, 44.44 \%$ y $11.11 \%$ de excelente, buena y regular calidad cuyo tamaño promedio fue de $454.40 \pm 92.13 \mu \mathrm{m}, 2200 \pm 129.1 \mu \mathrm{m}$ y $2800 \mu \mathrm{m}$ respectivamente. Similar respuesta publicaron Pacheco et al. (2016) de 57.2\% de embriones de calidad excelente y $23.8 \%$ de embriones de calidad buena en alpacas.

\section{CONCLUSIÓN}

Con el uso de los agentes capacitantes PHE y Heparina en medio de fecundación se obtuvo mayor porcentaje de clivaje, mórulas, blastocistos y correspondía a una mayor proporción de calidad excelente.

\section{CONTRIBUCIÓN DE AUTORES}

La concepción y diseño del estudio (WPG), adquisición de datos (WPG), análisis e interpretación de datos (WPG, MC, $\mathrm{CO})$, redacción del artículo (WPG, MC, CO), adquisición y administración de Fondos $(M C)$, aprobación definitiva de la versión a presentar (MC).

\section{CÓDIGO DE ÉTICA}

Los autores declaran que el estudio presentado se ha llevado a cabo de acuerdo con el Código de Ética para los experimentos con animales, tal y como se refleja en la normativa:

http://ec.europa.eu/environment/chemicals/lab_animals/legi sl ation_en.htm.

\section{CONFLICTO DE INTERESES}

Los autores firmantes del presente trabajo declaran no tener ningún conflicto de interés personal o económico con otras personas $u$ organizaciones que puedan influir indebidamente con el presente manuscrito.

\section{AGRADECIMIENTOS}

Al personal especialista y asistentes encargados del Laboratorio de Biotecnología Reproductiva de la Estación Experimental Agraria Canaán y a la Universidad Nacional de San Cristóbal de Huamanga por promover el desarrollo de este estudio.

\section{REFERENCIAS}

- Ahuja C, Montiel F, Pérez P, Gallegos J. Medio alternativo para la producción in vitro de embriones bovinos. Zootecnia Tropical. 2009; 27(3): 1-8.

- Andrews JC, Bavister B. Hamster Zonae Pellucidae Cannot Induce Physiological Acrosome Reactions in Chemically Capacitated Hamster Spermatozoa in the Absence of Albumin. Biology of Reproduction. 1989; 41(1):117-122.

- Arriaga I, Huanca W, Terreros M, Becerra J, García P, Ampuero A. Efecto de Temperatura y Tiempo de Almacenamiento de Ovarios de Alpacas sobre la Tasa de Maduración y División in vitro de Ovocitos. RIVEP. 2014; 25(4): 477- 486.
- Brogliatti GM, Palasz AT, Rodriguez-Martinez H, Mapletoft RJ, Adams GP. Transvaginal collection and ultrastructure of llama (Lama glama) oocytes. Theriogenology. 2000; 54(8): 1269-1279.

- Gomez O, Choque D, Henao F, Escobedo M, Valverde N. Comparación de tres métodos de recuperación de complejo ovocitos-cúmulos (COCs) de alpacas recuperados de ovarios postmorten en camal. SPERMOVA. 2013; 3(1): 103-104.

- Cabrera P, Yoong W, Gamarra G. Evaluación de la fertilidad in vitro del semen de toros jóvenes nacionales en ovocitos provenientes de ovarios de animales beneficiados. Revista de Investigaciones Veterinarias del Perú. 2009; 20(1):28-32

- Cardenas O, Sapana R, Gonzales M, Mamani R. Algunas Características de los Embriones Colectados de Vicuña (Vicugna vicugna) en el CIP Quimsachata del INIA-Puno. Revista de Investigación Altoandina. 2015; 17(3): 449 152.

- Clement-Sengewald A, Palma G, Brem G. Biotecnología en producción animal. Transferencia de embriones y biotecnología de la reproducción de la especie bovina. 1993;13-24.

- Contreras H, Olaguivel F, Naveros F. Evaluación de la calidad de embriones producidos por fertilización in vitro en alpacas (Vicugna pacos). In Urviola Gómez NC, editor. MEMORIAS de la XXXVII Reunión Científica Anual de la Asoiacion Peruana de Produccion Animal. Abancay; 2014. 148-151.

Accesado https://www.researchgate.net/profile/Angel_R2/publicat ion/341766733_MEMORIAS_DE_LA_XXXVII_REUNION_ CIENTIFICA_ANUAL_DE_LA_ASOCIACION_PERUANA_DE _PRODUCCION_ANIMAL/links/5ed2a 1 b092851c9c5e6 $71954 / M E M O R I A S-D E-L A-X X X V I I-R E U N I O N-C I E N T I F I C A-$ ANUAL-DE-LA-ASOCIACION-PERUANA-DEPRODUCCION-ANIMAL.pdf\#page $=263$

- Dapino DG, Marini PE, Cabado MO. Effect of heparin on in vitro capacitation of boar sperm. Biological research. 2006; 39(4): 631-639.

- Gonella AM, Atuesta JE, Bernal SM, Chacon L. Generalidades de la producción de embriones bovinos in vitro. Revista de Investigación Agraria y Ambiental. 2013; $4(1): 65-80$.

- El-Shahat KH, Taysser MI, Badr MR, Zaki KA. Effects of penicillamine, hypotaurine, and epinephrine on motility, hyperactivity, acrosome reaction of fresh ram sperm. Asian Pacific Journal of Reproduction. 2017; 6(6): 283-288.

- First NL, Parrish JJ. In Vitro fertilization of ruminants. J Reprod Fertil Suppl. 1987;34:151-65.

- Gonçalves FS, Barretto LS, Arruda RP, Perri SH, Mingoti GZ. Heparin and penicillamine-hypotaurine-epinephrine (PHE) solution during bovine in vitro fertilization procedures impair the quality of spermatozoa but improve normal oocyte fecundation and early embryonic development. In Vitro Cell Dev Biol Anim. 2014;50(1):39-47.

- Herradón P, Quintela L, Becerra J, Ruibal S, Fernandez M. Fecundación In vitro: Alternativa para la mejora genética en bovinos. Arch. Latinoamerica Producción Animal. 2007;
$15(1): 34$
41
Accesado. 
https://pdfs.semanticscholar.org/4511/a0c8996a033c5 24e501334a66e301b74c7a1.pdf

- Holt V, Pickard R. Role of reproductive technologies and genetic resource banks in animal conservation. Reviews of Reproduction. 1999; 4(3): 143-150.

- Huanca W. Biotecnologías reproductivas en camélidos sudamericanos. Archivos Latinoamericanos de Producción Animal. 2015; 23(1):1-4. Accesado http://www.produccionanimal.com.ar/produccion_de_camelidos/reproduccion/4 2-854.pdf

- Huanca W, Condori R, Chileno M, Garcia P, Cainzo J, Becerra J. Evaluación de Cuatro Tiempos de Cultivo sobre la Tasa de Maduración y División Posfecundación in vitro de Ovocitos de Alpaca. Revista de Investigaciones Veterinarias del Perú, 2014; 25(4): 468-476

- Huanca W, Cordero A, Huanca T, Adams G. Biotecnología reproductivas en camélidos sudamericanos domésticos: avances y perspectivas. Arch. Latinoam. Prod. Anim. 2007; 15(1):195-201.

Acceso http://www.bioline.org.br/pdf?la07052

- Pacheco J, Vélez V, Pezo D. Evaluación de la eficiencia de la transferencia de embriones interespecie entre alpacas y llamas obtenidos por ovulación simple. Revista de Investigaciones Veterinarias del Perú. 2016; 27(1): 64-69. Pahuara $L$, Naveros $M$. Producción in vitro de embriones bovinos (Bos taurus) en dos medios de cultivo. SPERMOVA. 2014; 4(1):54 - $57 . \quad$ Acceso http://spermova.pe/site2/files/Revistas/Rev.4\%20vol.1d el2014/54-5704_Pahuara-bovinos-54-57.pdf

- Palma GA. Producción in vitro de embriones. En Palma GA. Primera edición. Biotecnología de la Reproducción. 2001. Pp 225-282. INTA Balcarce.

- Ruiz B. In vitro production and transfer of embryos in South American Camelids: New opportunities and challenge. SPERMOVA. 2018; 8(1):54-60. DOI. 10.18548 /aspe/0006.06

- Pérez D, Zevallos A, Perez G. Comparación de sistemas de cultivo de embriones de alpacas. Revista de Investigación Altoandina. 2017; 19(2):157 - 164.

- Quintanilla M, Huanca L, Córdova G, Ampuero B, Benavides I. Efecto de la Suplementación del Medio de Maduración con Cisteamina y de Dos Medios de Cultivo (KSOMaa y SOF) en la Fecundación in vitro de Ovocitos Bovinos. Revista de Investigaciones Veterinarias del Perú. $2015 ; 26(3): 462-468$.

- Quispe G, Huanca, HT, Olivera L. Influencia de las hormonas folículo estimulante, luteinizante y gonadotropina corionica equina en la maduración in vitro de ovocitos y clivaje de embriones de alpaca. Revista investigadora de la escuela de posgrado. 2019; 8(1):974 - 985. Accesado http://www.revistaepgunapuno.org/index.php/investigac iones/article/view/774/246

- Ratto H, Silva M, Huanca T, Cordero A, Huanca W. Inducción de Superovulacion en camelidos. SPERMOVA. 2015; 5(2):253-257.

- Rodriguez L. Identificación y evaluación del mecanismo de activación del sistema proacrosina/acrosina en espermatozoides de alapca (Vicugna pacos). Tesis de biologa. Lima: UNMSM; 2012. Available from: https://cybertesis.unmsm.edu.pe/handle/20.500.1 2672/ 1411 .

- Ruiz J, Landeo L, Artica M, Ratto M, Correa J. Activación química de ovocitos de alpaca vitrificados después de la maduración in vitro. Revista de Investigaciones Veterinarias del Perú 2011 ; 22(3): p. 206-212.

- Stringfellow D, Seidel S. Manual of the International Embryo Transfer Society : a procedural guide and general information for the use of embryo transfer technology emphasizing sanitary procedures. International Embryo Transfer Society. Tercera ed. USA: Savoy IL; 1998.

- Terreros M, Huanca W, Arriaga I, Ampuero A. Efecto de Tres Crioprotectores en la Criopreservación de Espermatozoides Epididimarios de Alpaca. Rev. investig. vet. Perú. 2015; 26(3):420-426. Trasorras V, Miragaya M. Factores que afectan el desarrollo de la fecundación in vitro en camélidos

- Trasorras VL, Miragaya MH. Factors affecting the development of in vitro fertilization in camelids. SPERMOVA. 2016; 6(2): 104-106. http://dx.doi.org/10.18548/aspe/0004.03

- Urrego R, Tarazona A, Olivera M, Camargo O. Simplification of oocytes fertilization during in vitro production of bovine embryos. Rev. Colom. Ciencias Pecuarias. 2008; 21:398 - 402.

- Vasquez NF, Perez MG, Olivera LV, Perez UH. Efecto de dos Métodos de Colección sobre la Cantidad y Calidad Ovocitaria de Alpacas (Vicugna pacos) y Llamas (Lama glama) post mórten. Revista de investigaciones Altoandinas. $2015 ; 17(3): 331-340$. 